\title{
The Evidence of Interdisciplinary Teamwork in the Rehabilitation of Stroke Patients with Aphasia
}

\author{
Signe Vallumrød1* ${ }^{*}$ Tone Knudsen Oddvang², Elisabeth Severinsson ${ }^{1}$ \\ ${ }^{1}$ Department of Nursing Science, Centre for Women's, Family and Child Health, Faculty of Health Sciences, University College of South- \\ east Norway, Kongsberg, Norway \\ ${ }^{2}$ Department of Nursing Science, Nord University, Mo i Rana, Norway \\ Email: *signe.vallumrod@hbv.no
}

How to cite this paper: Vallumrød, S., Oddvang, T.K. and Severinsson, E. (2016) The Evidence of Interdisciplinary Teamwork in the Rehabilitation of Stroke Patients with Aphasia. Open Journal of Nursing, 6, 739-811.

http://dx.doi.org/10.4236/ojn.2016.69079

Received: August 25, 2016

Accepted: September 26, 2016

Published: September 29, 2016

Copyright $\odot 2016$ by authors and Scientific Research Publishing Inc. This work is licensed under the Creative Commons Attribution International License (CC BY 4.0).

http://creativecommons.org/licenses/by/4.0/

\begin{abstract}
The aim of this review was to investigate the evidence of interdisciplinary teamwork in the rehabilitation of stroke patients with aphasia. A total of 248 studies were read and nine included. The papers were analysed and data were extracted by categorizing the four components of rehabilitation: assessment, goal setting, intervention and reassessment. The results revealed that interdisciplinary teamwork was a prerequisite for rehabilitation and that nurses' position in post-stroke care was unclear and limited. In addition, rehabilitation strategies, interdisciplinary cooperation, education and training are important aspects of the rehabilitation process. This study highlights the need for one valid and reliable assessment tool that incorporates communication problems. In conclusion, persons with aphasia should be more involved in their own rehabilitation, which means that the interdisciplinary team members must be educated to communicate appropriately with them.
\end{abstract}

\section{Keywords}

Stroke, Aphasia, Communication, Interdisciplinary Team, Rehabilitation, Assessment Tool

\section{Introduction}

Approximately 15 million people suffer a stroke annually, of whom around 6.7 million die as a result [1] [2]. Despite the fact that the mortality rate has decreased in recent decades, stroke remains the second greatest cause of death all over the world [3] and is one of the main causes of limitations in daily activity defined as disability [4]. Stroke survivors suffer from a wide variety of disabilities that limit their ability to perform the activities of daily living (ADL), as well as different degrees of physical, cognitive, emo- 
tional and social limitation [5]. As a disabling disorder, stroke can be classified within the framework of the WHO International Classification of Function, Disability and Health (ICF), which encompasses health and health-related domains, disability and disease, impairments, activity limitations and participation restrictions. As the functioning and disability of an individual occur in a context, the ICF includes a list of environmental factors. The ICF is the WHO framework for measuring health and disability [6].

Aphasia, which influences most social activities, affects one third of stroke patients [7]. Aphasia differs in character and content in the various phases after stroke. The severity varies from mild or moderate problems to complete inability to identify or find words, or to speak and understand language, making it impossible to express oneself. The linguistic disorders differ across aphasia types and include difficulty in understanding the meaning of words (semantic disorder), trouble in producing word sounds (phonologic disorder) and problems in constructing sentences (syntactic disorder) [8]. Difficulties of speaking, writing and reading change the status of persons with aphasia from independence to dependence, sometimes leading to a life dominated by therapy, concentration problems and a drop in material and economic standards, in addition to limited access to information and communication technologies [4] [5] [9]. The subjective experiences of persons with aphasia seem to be isolation, boredom, bewilderment, fear, anger, shame, apathy, hopelessness, resignation and depression [10]. Because communication constitutes the key to social participation [8], the healthcare services should pay more attention to the delivery of stroke chronic care, where effective rehabilitation strategies are important [3]. A prerequisite for improving stroke rehabilitation focuses on stroke survivors' impairments, as many people survive stroke and are forced to continue life with aphasia and communication difficulties. Aphasia strikes like greased lightning, threatening the person's autonomy, independence and ability to express basic needs. Due to the fact that communication affects most human activities, aphasia rehabilitation should be prioritized from the start and followed up in the chronic stage by a competent community based rehabilitation team to reduce or eliminate activity limitation and restrictions on participation [6] [11]. Long-term consequences of stroke constitute a top-10 research priority, which includes helping stroke survivors and their families to cope with speech problems [12].

Speech problems require rehabilitation, which after stroke is described as long-term and process dependent. Stroke rehabilitation typically entails a cyclical process involving: 1. Assessment, to identify and quantify the patients' needs; 2 . Goal setting, to define realistic and attainable goals for improvement; 3. Intervention, to enable progress towards agreed goals for improvement; and 4. Reassessment, to assess progress towards agreed goals [4]. An important strategy is to conduct an assessment prior to rehabilitation in the area of communication, in order to reduce the suffering caused by social isolation, activity limitation and participation restrictions, as well as to diminish the consequences of the health burden [13]. Stroke units with an interdisciplinary rehabilitation team competent in speech and language therapy, medical therapy, nursing, occupational therapy and physiotherapy should be established to provide optimal rehabilitation for stroke patients [4]. An interdisciplinary approach is essential for the reha- 
bilitation of the patient.

Aim

The aim of this review was to investigate the evidence of interdisciplinary teamwork in the rehabilitation of stroke patients with aphasia.

\section{Methods}

\subsection{Review Question}

The review question addressed was: How is the process of assessment, goal setting, intervention and reassessment applied by interdisciplinary teams in the rehabilitation of stroke patients with aphasia?

\subsection{Search Strategy, Data Sources and Screening}

Searches were conducted in online databases (Embase, Ovid Medline, Cinahl, Cochrane Library, Proquest and Web of Science). The following key-words were systematically searched for, both separately and in combination with AND and OR: stroke, aphasia, communication impairment, language tests/hearing test, communication, speech, language, hearing, verbal, evaluation, mapping, assessment, check-up, examination and screening. The first search, which was broad, took place in January 2015 in three databases, Embase, Ovid Medline and Cochrane Library, and resulted in 1206 hits. The second search in March, 2015 was refined and key search terms included: stroke, aphasia, communication, interdisciplinary and rehabilitation. The MeSH headings and free text terms were combined to form the more specific terms mentioned above. An example of the search in one of the main databases, Ovid MEDLINE is presented in Table 1.

Table 1. An example of the search in Ovid Medline

\begin{tabular}{|c|c|c|}
\hline$\#$ & Searches & Results \\
\hline 1 & $\exp { }^{\star}$ Stroke/ & 67,680 \\
\hline 2 & exp ${ }^{\star A p h a s i a / ~}$ & 7631 \\
\hline 3 & $\begin{array}{l}\text { stroke or brain adj -infarct }{ }^{*} \text { or ischemia* or attack or insult or hemorrhage } \\
\text { or cerebral hemorrhage or cerebrovascular accident tw. }\end{array}$ & 164,509 \\
\hline 4 & aphasia $^{*}$ or communication impairment ${ }^{*}$ adj10, stroke or poststroke .tw. & 992 \\
\hline 5 & or/1 - 4 & 186,866 \\
\hline 6 & exp communication/ & 374,275 \\
\hline 7 & communication.tw. & 143,022 \\
\hline 8 & 6 or 7 & 482,509 \\
\hline 9 & interdisciplinary communication/ or exp.patient care team/ & 64,723 \\
\hline 10 & interdisciplin $^{*}$ or multidisciplin*.tw. & 69,984 \\
\hline 11 & 9 or 10 & 121,925 \\
\hline 12 & rehabilitation/or "rehabilitation of speech and language disorders"/ & 16,678 \\
\hline 13 & rehabilitati $^{*}$ or habilitat ${ }^{\star}$. tw. & 111,432 \\
\hline 14 & 12 or 13 & 118,092 \\
\hline 15 & 8 and 11 and 14 & 841 \\
\hline 16 & 5 and 15 & 91 \\
\hline
\end{tabular}


Studies of aphasia due to causes other than stroke were excluded, as were studies conducted before 2005. Two of the authors (S.V., T.O.) assessed the data extracted. A total of 248 titles met the inclusion criteria, of which nine were included for quality assessment. One study [14] was acquired at the Norwegian Stroke Conference 2015, which we attended. The retrieval process is presented in Figure 1.

\subsection{Inclusion and Exclusion Criteria}

The inclusion criteria were: 1) peer-reviewed research; 2) published in the English language; 3 ) studies focusing on the stroke rehabilitation process; 4) studies from the perspective of interdisciplinary teamwork in the rehabilitation process; and 5) studies that focused on experiences of communication with patients with aphasia. Supplements, theoretical frameworks, review articles and grey literature were excluded.

\subsection{Quality Assessment}

Each identified article was appraised using the PRISMA checklist of items to describe and analyse the quality [16]. All included articles were reviewed twice by the first two authors, after which they were checked by the third author in order to achieve consensus on the selection.

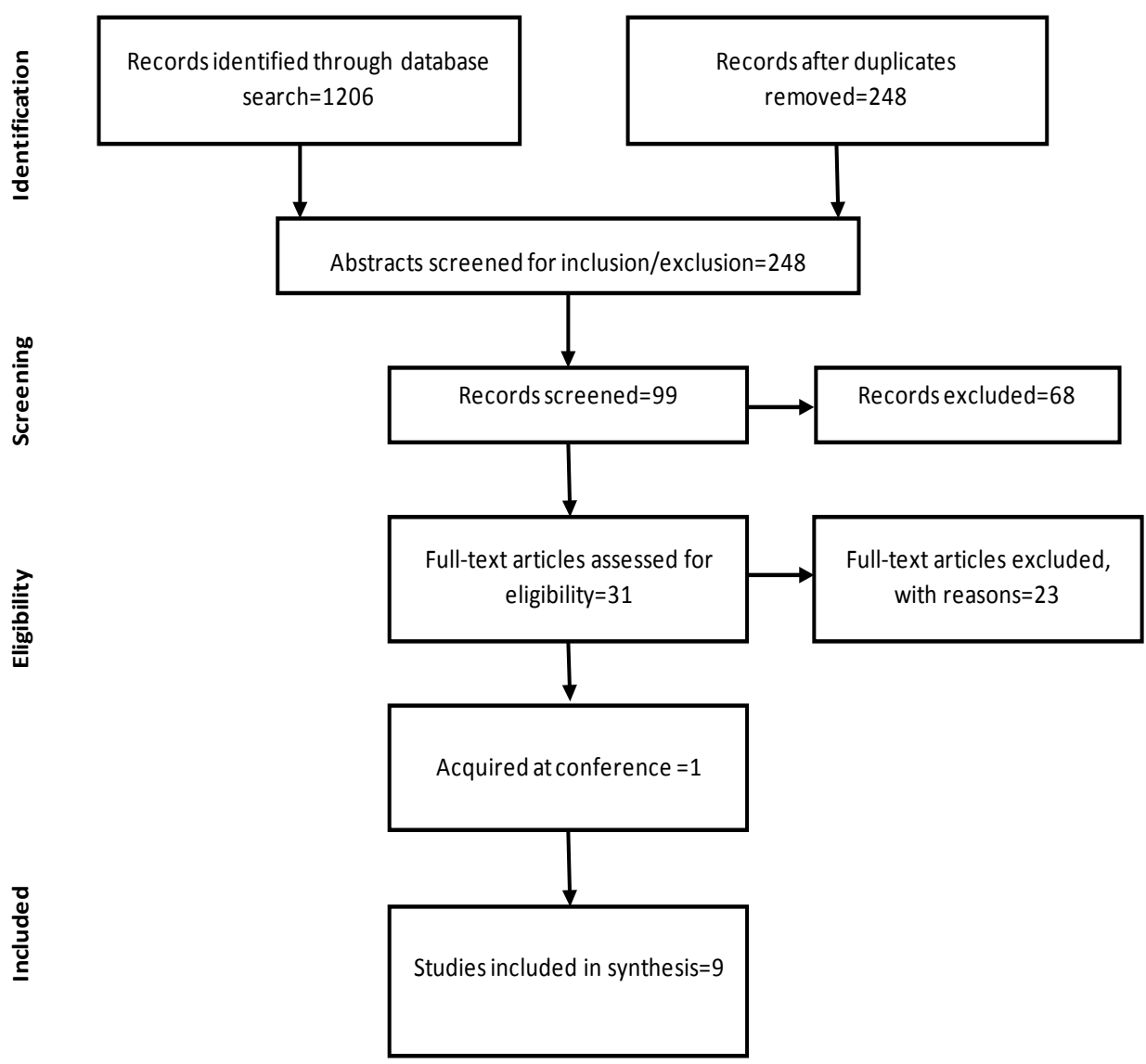

Figure 1. Flow-chart of the included studies [15]. 


\subsection{Data Extraction}

The papers were read thoroughly several times by the first two authors (S.V. \& T.O.) both separately and together. The content was discussed and reread before data extraction. Data were extracted from the nine papers by systematizing: author, country, year of publication, design, sample, analysis, aim and main findings. Details of the studies included in the review are presented in Table 2, and main findings are highlighted by cursive italic fonts.

\subsection{Assessment of Methodological Quality}

The methodological quality of the included studies was thoroughly assessed by two of the authors (SV, TKO) using a modified version of the Norwegian Knowledge Centre for Health Services (NOKC) check-list for cross sectional studies [17]. This check-list is a tool for assessing the degree to which the methodology of the studies encompasses the risk of systematic bias. The check-list contains eight questions assessing: 1. Population, 2. Sampling methods, 3. Comparison of respondents and non-respondents, 4. Response rate, 5. Data collection procedures, 6 . Reliability and validity, 7. Statistical methods and 8. Ethical considerations. Studies that fulfilled more than $50 \%$ of the criteria were rated as "Acceptable". Although one study was rated "Low" in terms of methodological quality as the methodology used did not appear to match the check-list criteria, it was deemed important to include its content. When in doubt, we consulted the third author (ES). No studies were excluded due to low quality. Methodological shortcomings mainly concerned criteria 3 and 8 , and demonstrated in Table 3.

\section{Results}

The nine included studies were analysed and data extracted from them by categorizing the four components of rehabilitation; assessment, goal setting, intervention and reassessment [4]. The particular shared characteristics of assessment, intervention and reassessments are exemplified in Table 4. Goal setting is presented under sub-heading 3.1.2.

\subsection{The Components of Rehabilitation}

Opportunities for and barriers to an optimal rehabilitation are interpreted and presented under the following headings; assessment and assessment tools, goal setting, interventions and reassessment. A brief outline of the main positive and negative outcomes of rehabilitation of stroke patients with aphasia is presented in Table 5.

\subsubsection{Assessment and Assessment Tools}

Assessment tools that explore the whole person are useful for the rehabilitation of language [11] [19] [21] [22]. In one study, the team members had a collective responsibility for person-centred assessment [11]. The inclusion of family members and next of kin is valuable for understanding the patient as a person [2] [11] [14] [19] [20] [23]. The ICF domains are fundamental for the development of new tools [19]. Assessment of activity, participation and environment is important [11] [14] [19]. A user-friendly 
Table 2. Details of the included studies.

\begin{tabular}{|c|c|c|c|}
\hline $\begin{array}{c}\text { Author Country } \\
\text { Year }\end{array}$ & $\begin{array}{l}\text { Design Sample } \\
\text { Analysis }\end{array}$ & Aim & Findings \\
\hline $\begin{array}{l}\text { 1) Fens et al. } \\
\text { The Netherlands } \\
2015\end{array}$ & $\begin{array}{l}\text { Longitudinal mixed methods design. } \\
\text { Intervention. Both quantitative and } \\
\text { qualitative outcomes. } \\
\text { Structured assessments, interviews and } \\
\text { self- administered Questionnaires. } \\
77 \text { stroke patients, } 59 \text { caregivers and } \\
4 \text { SCC }\end{array}$ & $\begin{array}{l}\text { To examine process-related factors } \\
\text { that could have influenced the } \\
\text { effectiveness of the intervention in } \\
\text { follow-up care after stroke }\end{array}$ & $\begin{array}{l}\text { Healthcare professionals who perform the } \\
\text { assessment need special training in effective } \\
\text { intervention and referral options for problems such } \\
\text { as cognition and fatigue. } \\
\text { GPs should be more involved in follow-up care }\end{array}$ \\
\hline $\begin{array}{l}\text { 2) } \\
\text { Matos et al. } \\
\text { Portugal } \\
2014\end{array}$ & $\begin{array}{l}\text { In-depth, semi-structured and focus } \\
\text { group interviews. } \\
\mathrm{N}=38 \text { individuals who live or work } \\
\text { with aphasia } \\
\text { PWA }=14, \mathrm{FM}=14 . \\
\text { The inclusion criteria included no } \\
\text { cognitive disturbances and no sign of } \\
\text { clinical depression. SLT = 10, average } \\
12.4 \text { years of experience. } \\
\text { Content analysis }\end{array}$ & $\begin{array}{l}\text { To explore and understand the } \\
\text { consequences of stroke with } \\
\text { aphasia for daily life from the } \\
\text { perspectives of people with aphasia } \\
\text { and those who live or work with } \\
\text { them }\end{array}$ & $\begin{array}{l}\text { Consequences of stroke and aphasia were reported, } \\
\text { such as; body function and body structure, mental } \\
\text { functions, neuro musculoskeletal and movement } \\
\text { related functions. The consequences of stroke and } \\
\text { aphasia have a considerable impact on daily life. } \\
\text { SLTs should use ICF-domains as a common } \\
\text { framework in patient-centred interdisciplinary } \\
\text { rehabilitation. } \\
\text { Patients with aphasia rate rehabilitation of } \\
\text { communication and autonomy higher than FMs } \\
\text { and SLTs. } \\
\text { Professional practice in Portugal needs to be } \\
\text { changed in order to integrate these findings }\end{array}$ \\
\hline $\begin{array}{l}\text { 3) } \\
\text { Aldous et al. } \\
\text { Australia } \\
2014\end{array}$ & $\begin{array}{l}\text { Online survey } \\
51 \text { respondents } \\
\text { Statistical analysis }\end{array}$ & $\begin{array}{l}\text { To investigate common practices } \\
\text { of speech-language pathologists } \\
\text { involved in assessments of } \\
\text { decision-making capacity for } \\
\text { persons with aphasia. }\end{array}$ & $\begin{array}{l}\text { Various formal and informal methods were used for } \\
\text { assessing capacity. Discussion among } \\
\text { interdisciplinary team members was reported to } \\
\text { have the greatest influence on their } \\
\text { recommendations. SLTs expressed dissatisfaction } \\
\text { with current protocols for capacity assessment and } \\
\text { required further education and training. }\end{array}$ \\
\hline $\begin{array}{c}\text { 5) } \\
\text { Scholberg \& } \\
\text { Sunnerhagen Norway } \\
2011\end{array}$ & $\begin{array}{c}\text { Case study } \\
\text { Data from four patient charts }\end{array}$ & $\begin{array}{l}\text { To communicate the need for and } \\
\text { benefits of comprehensive } \\
\text { rehabilitation and a standardized } \\
\text { approach to patients with LIS. }\end{array}$ & $\begin{array}{l}\text { The nurse and nurse's assistants are especially close } \\
\text { to patients with LIS and considered valuable } \\
\text { members of the LIS team. Patients with LIS require } \\
\text { a skilled team to provide help and find alternative } \\
\text { means of communication. } \\
\text { The need for more assistance to adapt to alternative } \\
\text { communication should be considered. } \\
\text { Centralization of a competent interdisciplinary } \\
\text { team with special skills is essential. There is a need } \\
\text { for an international network to improve skills and } \\
\text { the quality of rehabilitation for patients with LIS. }\end{array}$ \\
\hline $\begin{array}{l}\text { 6) } \\
\text { Clarke } \\
\text { UK } \\
2010\end{array}$ & $\begin{array}{l}\text { Grounded theory approach. } \\
220 \text { hours of participant observation, } \\
\text { semi-structured interviews with } \\
34 \text { team members and } 8 \text { patients }\end{array}$ & $\begin{array}{l}\text { To understand and explain how } \\
\text { teamwork was achieved and } \\
\text { maintained in two stroke } \\
\text { rehabilitation units. }\end{array}$ & $\begin{array}{l}\text { The core category 'opportunistic dialogue' was } \\
\text { based on four interrelated and interdependent } \\
\text { categories; positive about stroke, learning and } \\
\text { working together, concern for persons and inclusive } \\
\text { team culture. This included both systematic and } \\
\text { seize-the-moment interdisciplinary practice. }\end{array}$ \\
\hline
\end{tabular}




\section{Continued}

\begin{tabular}{|c|c|c|c|}
\hline $\begin{array}{l}\text { 7) } \\
\text { Ross et al. } \\
\text { UK } \\
2009\end{array}$ & $\begin{array}{l}\text { Case-study: Mixed methods- } \\
\text { questionnaires, qualitative evaluation, } \\
\mathrm{N}=107 \text { staff working with stroke } \\
\text { during their training, 2005-2008 }\end{array}$ & $\begin{array}{l}\text { To describe the development, } \\
\text { content and evaluation of an } \\
\text { in-service interdisciplinary training } \\
\text { programme } \\
\text { on psychological and } \\
\text { communication problems after } \\
\text { stroke }\end{array}$ & $\begin{array}{c}\text { The trained staff had confidence in their knowledge } \\
\text { and recognition of the basic management of } \\
\text { communication, cognitive and emotional problems } \\
\text { after stroke. }\end{array}$ \\
\hline 8) & $\begin{array}{l}\text { Multi-methods approach: } \\
\text { questionnaires, focus-groups and } \\
\text { workshops. }\end{array}$ & To identify and describe the & $\begin{array}{l}\text { Both groups preferred accredited stroke education. } \\
\text { Care home nurses required more training in stroke } \\
\text { assessment, rehabilitation and acute interventions, } \\
\text { senior care assistants required more education in }\end{array}$ \\
\hline $\begin{array}{l}\text { Smith et al. } \\
\text { UK }\end{array}$ & $\begin{array}{l}\text { A stratified random selection of } 16 \\
\text { private, } 3 \text { voluntary and } 6 \text { NHS }\end{array}$ & $\begin{array}{l}\text { educational needs of care home } \\
\text { staff when caring for residents with }\end{array}$ & $\begin{array}{l}\text { managing depression, general stroke information } \\
\text { and communicating with dysphasic residents. }\end{array}$ \\
\hline 2008 & $\begin{array}{l}\text { healthcare homes, from which a sample } \\
\text { comprising } 115 \text { trained nurses and } 19 \\
\text { senior care assistants was recruited }\end{array}$ & stroke related aphasia. & $\begin{array}{c}\text { Senior care assistants needed more information on } \\
\text { interdisciplinary team work, while care home nurses } \\
\text { were more concerned with ethical decision-making, } \\
\text { accountability and goal setting. }\end{array}$ \\
\hline $\begin{array}{l}\text { 9) } \\
\text { Knight et al. } \\
\text { Australia } \\
2006\end{array}$ & $\begin{array}{l}\text { Qualitative mixed methods; Participant } \\
\text { observation and semi-structured } \\
\text { interviews. } \\
7 \text { stroke patients aged } 41 \text { - } 99 \text { years; } 2 \\
\text { with and } 5 \text { without aphasia in acute } \\
\text { hospital settings }\end{array}$ & $\begin{array}{l}\text { To describe how health } \\
\text { information is provided to stroke } \\
\text { patients and their perceptions of } \\
\text { information provision. }\end{array}$ & $\begin{array}{l}\text { Only } 17.5 \% \text { of communication time was spent } \\
\text { providing information. Patients with aphasia } \\
\text { received less information time and content than } \\
\text { patients without aphasia. Patients left the stroke } \\
\text { unit with little information on aphasia. Health } \\
\text { information to patients with aphasia was only given } \\
\text { when their significant others were present. } \\
\text { Transmission barriers such as poor vision, impaired } \\
\text { hearing or language difficulties (aphasia) were } \\
\text { described as hindrances that led to a lack of detailed } \\
\text { information. Only verbal information was provided } \\
\text { to patients with aphasia, even though they would } \\
\text { prefer written information. The pattern of } \\
\text { information provision was infrequent, unplanned } \\
\text { and erratic. }\end{array}$ \\
\hline
\end{tabular}

SCC $=$ Stroke Care Coordinators; ACAS = Assessment Consequences after Stroke, GP = General Practitioner, PWA = People with Aphasia, SLT = Speech and Language Therapists, FM = Family Members, LIS = Locked-In Syndrome, PSC = Post Stroke Checklist.

Table 3. Methodological quality assessment of the included studies.

\begin{tabular}{|c|c|c|c|c|c|c|c|c|c|}
\hline \multirow[t]{2}{*}{ First author, Year } & \multicolumn{8}{|c|}{ Quality assessment question* } & \multirow[t]{2}{*}{ Total assessment quality } \\
\hline & 1 & 2 & 3 & 4 & 5 & 6 & 7 & 8 & \\
\hline Fens 2015 & $\mathrm{Y}$ & $\mathrm{Y}$ & $\mathrm{N}$ & $\mathrm{Y}$ & $\mathrm{Y}$ & $\mathrm{Y}$ & $\mathrm{Y}$ & $\mathrm{Y}$ & Acceptable \\
\hline Aldous 2014 & $\mathrm{Y}$ & $\mathrm{Y}$ & NI & $\mathrm{N}$ & $\mathrm{Y}$ & NI & $\mathrm{Y}$ & NI & Acceptable \\
\hline Philp 2013 & NI & $\mathrm{Y}$ & NI & $\mathrm{Y}$ & $\mathrm{Y}$ & $\mathrm{N}$ & $\mathrm{NI}$ & $\mathrm{NI}$ & Acceptable \\
\hline Clarke 2010 & $\mathrm{Y}$ & $\mathrm{Y}$ & NI & $\mathrm{Y}$ & $\mathrm{Y}$ & NI & NI & $\mathrm{Y}$ & Acceptable \\
\hline Ross 2009 & NI & $\mathrm{Y}$ & NI & $\mathrm{Y}$ & $\mathrm{Y}$ & $\mathrm{Y}$ & $\mathrm{Y}$ & NI & Acceptable \\
\hline Smith 2008 & $\mathrm{Y}$ & $\mathrm{Y}$ & NI & $\mathrm{Y}$ & $\mathrm{Y}$ & $\mathrm{Y}$ & $\mathrm{Y}$ & $\mathrm{Y}$ & Acceptable \\
\hline Knight 2006 & $\mathrm{Y}$ & $\mathrm{Y}$ & NI & $\mathrm{N}$ & $\mathrm{Y}$ & NI & $\mathrm{NI}$ & $\mathrm{Y}$ & Acceptable \\
\hline
\end{tabular}

Note: $\mathrm{Y}=$ Yes, $\mathrm{N}=\mathrm{No}, \mathrm{NI}=$ No information. ${ }^{\star}$ Quality assessment questions: 1 . Was the population from which the sample was drawn clearly defined? 2 . Were sampling methods adequate? 3. Was it explained whether (and how) the participants who agreed to participate differed from those who refused? 4 . Was the response rate adequate? 5 . Were procedures for data collection standardized? 6 . Were measures shown to be reliable and valid? 7 . Were the statistical methods appropriate? 8 . Were ethical issues considered? 
Table 4. Categories extracted from the studies.

Assessment
The ACAS is a new assessment tool developed for the home
care service and inpatient rehabilitation that highlights the
activities of daily life and includes communication. The ACAS
was not appropriate for patients with severe aphasia or
cognitive impairment. Stroke nurses assessed stroke patients
[18].

In contrast to SLTs, PWA and FMs value the mental functions of language, rating energy and drive functions as the most important. Clinicians need tools that identify contextual and personal factors [19].

SLTs commonly contribute to the assessment of the decision making capacity of persons with aphasia in both inpatient and rehabilitation settings.

The scope of the assessment by SLTs and their contribution to the interdisciplinary team are not clear. The SLTs use a wide variety of formal assessment tools and informal assessment. [2]

A PSC assessment tool was developed. The PSC is a brief and easy to use tool for identifying long-term problems [20].

Immediate assessment is important for the rehabilitation process and utilization of the inpatient period [21].

Interdisciplinary team member negotiation is necessary to improve the quality of assessments [11].

Assessment of mood, cognitive problems and communication disabilities was improved, leading to less avoidance of patients with aphasia [22].

Care home nurses required accredited education and training in stroke assessment.

The senior care assistants required more knowledge about team work in the assessment procedure [23].

Aphasia seems to lead to discrimination against patients in the assessment. The international Classification of functioning, disability and health is relevant for assessment. Patients with aphasia are negatively labelled [14].

\section{Intervention}

The follow-up care should be tailored to a structured assessment procedure and individual needs. Few patients with aphasia were referred to [18]. the interdisciplinary team [18].

The interdisciplinary team should cooperate and include FMs to contribute to improvements, even for chronically aphasic persons [19].

Successful interventions are dependent on a skilled multidisciplinary team [21].

Interventions were supervised continuously [11].

\section{Reassessment}

The ACAS was used as a structured referral system to guarantee continuity.

The interdisciplinary team was more alert and confident in the interventions [22].

Collaboration between SLTs, PWA and FMs is important for the provision of appropriate rehabilitation [18] [19].

Referrals for treatment should be followed up using the PSC [20].

A skilled team is required to reassess the skills and needs of patients with LIS [21].

. In order to perform relevant interventions senior Core team members shared knowledge, care assistants required education and training in experiences and values in negotiations how to communicate with dysphasic residents with cognitive, communication and speech problems [23]. about decisions pertaining to agreed goals [11].

Measurable standards and guidelines Interventions are poor if assessment and goal are warranted in the stroke rehabilitasetting are inadequate, which discriminates againsttion process to identify patient needs patients with aphasia [14].

ACAS = Assessment tool for long-term Consequences After Stroke; ICF = International Classification of Function, Disability and Health; SCC $=$ Stroke Care Coordinators; GP = General Practitioner; PWA = People With Aphasia; SLT = Speech and language therapists; SLP = Speech and Language Practitioner; FM = Family Members, LIS = Locked-In Syndrome; PSC $=$ Post Stroke Checklist.

assessment tool was developed by an international expert panel to standardize follow-up care for stroke patients [20]. Some assessment tools such as the ACAS were not appropriate for persons with severe aphasia [18]. Patients with aphasia are likely to be interpreted as having a passive role, therefore withdrawn patients require a more concerted effort [14].

In the assessment the main areas of language comprised; auditory, comprehension, 
Table 5. Positive and negative outcomes of rehabilitation for persons with aphasia.

\begin{tabular}{|c|c|}
\hline Positive aspects & Negative aspects \\
\hline $\begin{array}{l}\text { - Person centred assessment tool that covers ICF } \\
\text { domains } \\
\text { - Inclusion of persons with aphasia and their next of } \\
\text { kin } \\
\text { - Collective interdisciplinary responsibility and } \\
\text { collaboration } \\
\text { - Co-located interdisciplinary team } \\
\text { - Defined interdisciplinary team member roles } \\
\text { - Formal and informal education } \\
\text { - Sharing knowledge and skills }\end{array}$ & $\begin{array}{l}\text { - Use of non-appropriate assessment tools } \\
\text { - Poor communication skills when dealing with } \\
\text { - } \quad \text { persons with aphasia } \\
\text { of persons with aphasia. } \\
\text { - Lack of knowledge and skills pertaining to the } \\
\text { steps of the rehabilitation process } \\
\text { - Little knowledge of interdisciplinary team work } \\
\text { - Unclear team member roles } \\
\text { Less continuity by not including nurses as active } \\
\text { members of the team }\end{array}$ \\
\hline
\end{tabular}

verbal expression, reading and writing [2]. A variety of assessment tools were described in the included studies. Matos claims there is a need to develop a new assessment tool based on the ICF. It is important to consider all ICF domains in the rehabilitation of stroke patients and their language ability. Healthcare professionals require tools that explore the whole person and the entire situation [19]. Stroke causes impairment in language, physical ability and emotions. However, Matos claims that the social dimension is often disregarded in the assessment procedure. Tools such as Assessment for living with Aphasia and the Burden of stroke scale are suggested for exploring the situation of the whole person based on ICF domains [19]. However, such tools are not always appropriate for persons with aphasia. The ACAS, which was developed for inpatients as well as for the home care service in The Netherlands, was found to be unsuitable for patients with severe aphasia because they could be left without rehabilitation goals and relevant interventions [18]. Even from the start, assessment of patients with communication impairments due to aphasia is likely to be poor. Interdisciplinary team members interpret patients with aphasia to have a passive role [14].

A Post-stroke Checklist (PSC) was developed by international medical experts as a user-friendly tool for the identification of long term problems in stroke patients [20]. Assessment of persons with LIS prioritizes respiratory and nutritional status, communication skills and cognition. Family and next to kin are important for obtaining knowledge about the person [21].

Clinicians utilized both formal and informal assessments, as well as discussions with the multidisciplinary team and the patient's family members [2]. The main language areas (auditory, comprehension, verbal expression, reading and writing) were assessed. The patient's decision-making ability was included, especially in acute inpatient and inpatient rehabilitation settings. Assessing mood, communication and cognition was deemed essential [22].

\subsubsection{Goal Setting}

The patients' views and wishes are vital for defining meaningful goals and the input of family members can be helpful [21]. WHO goals pertaining to patient rights were not fulfilled, as a lack of information to patients with aphasia was revealed [14]. Important 
information on topics such as the causes and effects of stroke, recovery and prognosis, test results and the support available in the future was not provided to patients. Those with aphasia received less information and communication time compared to stroke patients without aphasia [14].

Social and emotional well-being was incorporated in the goalsetting by including information and involving families [11]. The goal for patients with LIS is threefold; to establish and maintain optimal respiration, nutrition and communication [21]. Quality of life goals became more visible to the members of the interdisciplinary team through the PSC tool [20].

\subsubsection{Interventions}

It is important to take cognition and fatigue into account to ensure effective interventions [18]. The PSC tool provides a common platform for performing quality of life interventions [20]. In order to constantly tailor the interventions they were negotiated both in structural meetings and on the spot [11].

In addition to life-supporting interventions, resources for communication and communicative skills such as eye winking should be included. To be able to interpret the patient's wishes and establish optimal communication, the staff should become familiar with adapting to and utilizing advanced communication equipment, as well as being open minded in the close relationship with the patient [21].

\subsubsection{Reassessment}

A structural referral system to guarantee continuity in long term chronic care is recommended [18]. The PSC provided the interdisciplinary team with a common referral system to use in the reassessment [20].

Both formal and spontaneous reassessment continuously occurred in the form of close negotiations between the members of the interdisciplinary team in order to achieve appropriate goals and interventions. Furthermore, unplanned dialogue took place when it became necessary to reconsider agreed goals [11]. Reassessment should reveal the communication skills of patients with LIS, their adaptation to advanced technology and whether more support is needed to communicate. Moreover, relevant competence should be harmonized with the needs of patients with LIS [21].

\subsection{Interdisciplinary Teamwork}

Interdisciplinary teamwork is a prerequisite for rehabilitation. The included studies highlight the variety of healthcare professionals involved in the rehabilitation of stroke patients with aphasia. The studies refer to SLTs, rehabilitation assistants, physiotherapists, occupational therapists, SCCs, nurses, nurse assistants, senior care assistants, healthcare assistants, dieticians, medical experts/physicians, social workers, a psychologist, an engineer and technical support. Some studies described next to kin as useful collaborative partners.

\subsubsection{Rehabilitation Strategies}

SLTs suggest that a broader interdisciplinary team is necessary to apply the ICF frame- 
work for patients with aphasia. FMs should be included to optimize the assessment of activity and participation. In Portugal, SLTs traditionally focus on linguistic impairments and activity limitations, and have no tradition of involving FMs [19]. Matos points out that the British National Stroke guidelines suggest that allied health professionals, health or social care workers and volunteers should have an increased role in an interdisciplinary intervention at the chronicstage of aphasia after stroke. The SLTs perceived such an intervention to be more valuable than previously appreciated. Matos stated that the assessment was performed by SLTs [19].

The team members' roles in the rehabilitation process were unclear [20]. The four main areas of language were assessed by 51 SLTs in acute and rehabilitation in-patient settings [2]. GPs might make an important contribution by identifying prognostic characteristics [18]. Psychologists could have a significant role in the interdisciplinary team due to the need to address the impact of the emotional changes that follow stroke and aphasia [19].

Clarke's study conducted at two stroke units in hospitals in Northern England focused on the close collaboration among team members when caring for stroke patients [11]. The close interdisciplinary collaboration in terms of sharing knowledge and skills facilitated negotiations (opportunistic dialogue) and led to the best problem-solving care in the rehabilitation of stroke patients. The sharing was both planned (i.e., formal meetings) and unplanned (i.e., seizing the moment). This collaboration went beyond the traditional features of teamwork and greatly benefitted the rehabilitation. In the opportunistic dialoguethe team members experienced person-centred assessment and a collective concern about the person with aphasia, which is an absolute prerequisite for successful rehabilitation. All team members were considered valuable for achieving the rehabilitation goals. By including nurses the study demonstrates that rehabilitation is not only the responsibility of therapy experts [11].

Nurses are mentioned as an essential part of the team caring for patients with LIS, as their assessment of the daily care is important. The skilled interdisciplinary team set shared goals, organised follow-up and reassessed skills [21]. Stroke patients need health information in the acute stroke unit, where three out of seven informants described nurses as the main information providers [14].

Stroke nurses specialized in long term care after stroke were responsible for monitoring patients in the rehabilitation process. They set goals alone without involving the other healthcare professionals in the interdisciplinary team [18].

Nurses and senior care assistants are the main staff categories in the care of persons with stroke [23]. These nurses experienced working in isolation with few opportunities for teamwork and expressed a strong need for interdisciplinary cooperation to increase the quality of the rehabilitation [23].

\subsubsection{Interdisciplinary Cooperation}

Patients living at home and their caregivers were referred to different healthcare professionals by the SCCs, but a cooperation strategy in the rehabilitation process was absent [18]. The rehabilitation team at Sunnaas Hospital in Norway is interdisciplinary 
and encompasses the different skills needed in the rehabilitation process. The team members considered interdisciplinary teamwork essential for successful rehabilitation. Patients with LIS constitute such a small group that even international teamwork is warranted to facilitate best practice in their rehabilitation [21]. Joint dialogue-based cooperation strategies are dependent on co-location of core team members, as well as regular meetings with collective thinking and engagement [11]. Moreover, joint dialogue is problem-oriented and emerges spontaneously due to team members observing problems and seizing the moment to solve them, irrespective of interdisciplinary status. The dialogue is also patient-oriented and closely linked to defined rehabilitation goals. Team members articulate knowledge, values, experiences, perceptions and beliefs [11]. In this opportunistic dialogue the rehabilitation process is based on negotiations between team members' perspectives [14]. One of the benefits of opportunistic dialogue is that teamwork makes it possible to go beyond the traditional focus on structural features. The result is shared competence and effectiveness in the rehabilitation process [11]. Allied health staff, nurses, health care assistants and therapy assistants worked together in groups of approximately 20 persons. SLTs, a primary care physician and a community continence adviser cooperated and linked the patient to specific referrals by using the PSC [20]. Interdisciplinary team members interpret patients with aphasia to have a passive role, thus patients with communication impairments are likely to be disadvantaged from the start [14].

\subsection{Education and Training}

There is an unmet need for learning more about interdisciplinary teamwork among senior care assistants and nursing home nurses [23]. The benefits of interdisciplinary teamwork became more integrated after a staff training programme, which led to teamwork competence and job satisfaction [22]. Allied health staff, nurses, health care assistants and therapy assistants also had formal sessions guided by psychologists, an occupational therapist and SLTs. This training resulted in increased knowledge and confidence, integrated team-working and the holistic management of patients [11]. An interdisciplinary training programme entitled "Training the trainers" was developed to support fragile communication following stroke and former stroke patients were involved in designing it. The result was less avoidance of communication with patients with aphasia and more support being offered [22].

Nursing home staff required more knowledge about interdisciplinary activities [23], as well as training and education in stroke assessment, utilizing assessment tools and goal-setting. Senior care assistants needed better skills in communicating with dysphasic patients [23], while nursing home nurses requested accredited education [23]. The interdisciplinary team needs training, while continuity can be ensured by using the same assessment tool and referral system every time. Healthcare professionals require knowledge about how cognition and fatigue influence interventions for persons with aphasia [18]. Ross' study developed an interdisciplinary training programme to increase staff knowledge in terms of recognition and basic management of emotional, 
cognitive and communication problems following stroke [22]. After completing the programme the interdisciplinary team members reported improved assessment skills and better management of mood, cognition and communication [22].

\section{Discussion}

The aim of this review was to investigate the evidence of interdisciplinary teamwork in the rehabilitation of stroke patients with aphasia. The review question addressed was: How is the process of assessment, goal setting, intervention and reassessment applied by interdisciplinary teams in the rehabilitation of stroke patients with aphasia?

As persons with aphasia and their next to kin rate the rehabilitation of communication skills as the most important aspect, it is necessary to identify components and factors that contribute to successful rehabilitation in this area. The goal is to design sustainable and beneficial assessment, goal setting, intervention and reassessment for the rehabilitation of persons suffering from aphasia.

\subsection{Making a Difference for Persons with Aphasia}

A problem is that healthcare professionals can misinterpret patients who suffer from aphasia after stroke. The aphasia might be understood as a vague response or lack of interest and cooperation [14]. This misinterpretation on the part of staff members can cause them to devote less attention and interaction time to patients [14], and difficulty reaching the point at which to start rehabilitation. Moreover, the emotional stress and social limitation experienced by patients with aphasia can be ignored from the start [5]. The fact that patients with aphasia are not informed about their status and prognosis might be demotivating for them [14]. When healthcare professionals' pattern of care is weak in the area of rehabilitation, it must be strengthened. As communication is a reliable key to social participation, patients with aphasia are dependent on tailored rehabilitation [4] [5] [9].

\subsection{The Starting Point and the Process of Rehabilitation}

Without an appropriate assessment there is no basis for rehabilitation, thus all approaches will be random. As time is a crucial factor, the assessment must start as soon as possible for in-patients [21]. Competence and confidence are required to make optimal use of the wide variety of available assessment tools. Evidence reveals that knowledge and training are essential for enabling staff members to utilize assessment tools [23]. Existing assessment tools and the ACAS were not always considered appropriate for stroke patients with aphasia or severe aphasia [2] [18]. The ICF seems to incorporate relevant factors for the assessment procedure, thus it is necessary to develop a new sustainable assessment tool based on the ICF [19] [24]. It is challenging to construct a user-friendly tool based on the ICF [20] [24]. The PSC was intended to focus on long-term assessment with an interdisciplinary approach based on the 11 relevant ICF areas for persons with impairment after stroke [20]. A prerequisite for successful rehabilitation of persons suffering from aphasia appears to be employing the ICF frame- 
work as a base for assessment by operationalizing the main components of functioning, disability and health. There is no doubt that for patients with aphasia, SLTs are the most competent professional category to carry out the assessment, set goals and decide how to intervene. The core improvements for persons with aphasia concern how language is transferred and applied to their real life [24]. Threats state that the question is how the ICF can contribute to improving the quality of life for persons with aphasia. Environmental factors influence patients' situation and have an impact on the assessment. The patient's condition can hinder or promote a successful assessment. Fatigue, depression, hunger, lack of sleep, pain, etc. can make a valid assessment impossible [23]. As patients with aphasia spend most of their time with nurses and senior care assistants, members of these two professional categories are essential for detecting such factors, thus facilitating a valid assessment.

\subsection{Interdisciplinary Team Work}

Impairments following a stroke are complex and require a highly complicated and specific rehabilitation, which must be provided by an interdisciplinary care team [4]. Of the healthcare professionals mentioned as part of the interdisciplinary teams that provide care to stroke patients, SLTs have the highest competence in the area of speech and language impairments. As nurses and nurse assistants spend a great deal of time close to patients with aphasia [22], they can facilitate continuity in the assessments, intervention and reassessment. Patients with aphasia receive less attention and are often negatively labelled [14]. This demands improved awareness and attention on the part of the nurses and nurse assistants to ensure that the patients are seen and communicated with.

This close relationship means that nurses are in a special position to assess the patients and conduct interventions in daily care situations [21], thus they have a central role inthe interdisciplinary team. However, stroke unit nurses did not appear to be well integrated in the interdisciplinary team [25]. There is an urgent need to re-examine the role of nurses in stroke rehabilitation to enable them to make a substantial contribution to the interdisciplinary work [11]. Nurses are not always aware of this responsibility. In-patients with stroke expected nurses to be the main information provider [14]. The fact that this is not the case means that there is unused potential in the rehabilitation process.

Different professional categories have a role in supporting the rehabilitation of patients with stroke [18]. However, the care team does not always function as an operational interdisciplinary team [11] [21]. While the interdisciplinary approach appears to function for patients with severe sequelae, our findings reveal that it tends not to function as well for patients with milder complications [2] [11] [18] [19] [23]. The question is which priority is given to active interdisciplinary rehabilitation for the group with milder complications and whether the team is designed to be goal oriented. Inefficient rehabilitation strategies could result in unused potential and reduce the patients' chances of regaining their ability to communicate. The time at which the intervention 
takes place and the amount of training are important for successful rehabilitation of aphasia after stroke. To achieve the best possible result, the whole team, including nurses and nursing assistants, must collaborate closely with each other and actively motivate, guide and stimulate the patient. Utilizing periods when the patient is awake, alert and motivated is crucial for success as it enables the amount of training to be increased and exercises to be transferred to different situations.

In our opinion, a successful rehabilitation team for persons with complications after stroke, especially those who suffer from aphasia, is one that collaborates closely and is co-located. Being unable to express oneself must be so full of hopelessness and fear that interpreting and facilitating rehabilitation best practice in stroke units and the community health services should be a high priority for closely collaborating interdisciplinary teams. To achieve this all health professionals, including nurses, must be integrated in the team, seize the right moments, take responsibility and interpret their role as important for the rehabilitation. A prerequisite for successful further rehabilitation in the community health service is the design of functional interdisciplinary teams that include nurses and nursing assistants.

\subsection{Education and Training}

A need for more education and training was one of the major findings in this review [2] [11] [18] [22] [23]. Studies show that the level of staff competence influences how patients with aphasia are communicated with [21]-[23]. A skilled team increases confidence and safeguards the quality of the rehabilitation process for stroke patients [11] [21] [22]. Results reveal greater confidence in communication with patients, use of assessment tools and in interdisciplinary collaboration after completion of a training programme [22] [23]. Staff members exhibited greater recognition and acceptance of the patients' speech problems, frustration and distress. Care for families and next of kin strengthened mutual collaboration and improved rehabilitation [14] [23]. Competence in using devices and confidence in the shared goals and strategies facilitated collaborative practice and improved the overall outcome for the person with aphasia [21].

Another way of increasing competence involves sharing professional knowledge by working in opportunistic dialogue [11]. In the team, the effect of learning and working together by sharing core skills led to a common understanding instead of professional defence. The whole team was aware of and shared the patients' goals, thus the members made a concerted effort to work towards them together, leading to successful rehabilitation. Sharing knowledge in the team increased motivation and engagement, while alternative ways of conceptualizing the rehabilitation interventions proved beneficial for patients [11]. Work satisfaction and enthusiasm make staff desirous for training [23].

Some studies mentioned experiences of designing and running training programmes [22]. To achieve a really practical and useful content, one study described how former stroke patients were recruited to assist in designing the training programme, as well as presenting some parts of it [22]. This was evaluated as a success. 


\section{Limitations of the Study}

This systematic review has some limitations. The number of included studies is few. After reviewing the literature search it turned out that our research question limited the amount of research that could be included due to the need for research on persons with aphasia. Although this review has been thoroughly evaluated by two of the authors (SV and TKO) who read the studies several times from different perspectives, there is still a possibility that we might have missed out on or misunderstood some of the information presented. To counter the possibility of undetected bias, differences in understanding and judgment were resolved by discussions between the authors, leading to a common understanding of, as well as consensus on, the interpretation of the analysed studies. Although some of the included qualitative studies have a small sample, we consider that it would be difficult to perform large studies on this topic as persons with aphasia constitute such a limited research field. The stroke research field is strong in terms of research from a neuroscience perspective, but poor from the perspective of aphasia rehabilitation. In our opinion, smaller in-depth studies can produce valuable and easily transferable information in this area.

\section{Conclusions}

Ignoring the rehabilitation of communication for patients with aphasia could influence the quality of the rest of their lives and become the difference between boredom or interest, inactivity or activity, social isolation or participation, dependence or independence and apathy or hope. This study highlights the need for one valid and reliable assessment tool that incorporates communication problems. Successful rehabilitation starts with the application of a relevant assessment tool. Assessment tools require tailored competence in order to fully exploit the starting point and subsequent steps of the rehabilitation process. Interdisciplinary collaboration towards shared goals in the rehabilitation of language is decisive for success. Each professional category in a successful rehabilitation team has a defined role. To perform as a successful team, co-location and close collaboration are crucial.

The studies in this review reveal that nurses' position in post-stroke care is unclear and limited. To achieve a valid assessment and successful rehabilitation, the roles of interdisciplinary team members and their collaboration strategies must be reorganized. The contribution of nurses and senior care assistants must be acknowledged as important for continuity, successful assessment and rehabilitation as a whole.

A need for formal and informal education, both on site and accredited, was detected. The design of relevant educational programmes should be the responsibility of universities and other educational institutions. Community health services, hospital stroke units and educational organisations should collaborate to design relevant training programmes. In addition, this review revealed a need for increased knowledge and skills among interdisciplinary team members in terms of interdisciplinary team work. Persons with aphasia should be more involved in their own rehabilitation process, which 
implies the necessity of educating interdisciplinary team members to communicate with them.

\section{Acknowledgements}

We want to thank Monique Federsel for reviewing the English language and Hege Sletsjøe, specialist Liberian, for her valuable help with the electronic search for articles. The study was supported by grants from the Centre for Women's, Family and Child Health, the University College of Southeast Norway.

\section{Contributors}

The study was design by S.V and T. O. S.V. coordinated the research. All authors participated in the data analysis. All authors contributed intellectually, proof read and approved the final manuscript. E.S. supervised the study.

\section{References}

[1] World Health Organization (2015) Cardiovascular Diseases (CVDs): Fact Sheet $\mathrm{N}^{\circ} 317$. http://www.who.int/mediacentre/factsheets/fs317/en/

[2] Aldous, K., Tolmie, R., Worrall, L. and Ferguson, A. (2014) Speech-Language Pathologists' Contribution to the Assessment of Decision-Making Capacity in Aphasia: A Survey of Common Practices. International Journal of Speech-Language Pathology, 16, 231-241. http://dx.doi.org/10.3109/17549507.2013.871751

[3] Feigin, V.L., Forouzanfar, M.H., Krishnamurthi, R., Mensah, G.A., Connor, M., Bennett, D.A., et al. (2010) Global and Regional Burden of Stroke during 1990-2010: Findings from the Global Burden of Disease Study. Lancet, 383, 245-254. http://dx.doi.org/10.1016/S0140-6736(13)61953-4

[4] Langhorne, P., Bernhardt, J. and Kwakkel, G. (2011) Stroke Rehabilitation. Lancet, 377, 693-702. http://dx.doi.org/10.1016/S0140-6736(11)60325-5

[5] Ellis, C., Grubaugh, A.L. and Egede, L.E. (2013) Factors Associated with SF-12 Physical and Mental Health Quality of Life Scores in Adults with Stroke. Journal of Stroke and Cerebrovascular Diseases, 22, 309-317. http://dx.doi.org/10.1016/j.jstrokecerebrovasdis.2011.09.007

[6] World Health Organization (2015) Disability and Health: Fact Sheet $N^{\circ} 352$. http://www.who.int/mediacentre/factsheets/fs352/en/

[7] Mazaux, J.M., Lagadec, T., de Seze, M.P., Zongo, D., Asselineau, J., Douce, E., et al. (2013) Communication Activity in Stroke Patients with Aphasia. Journal of Rehabilitation Medicine, 45, 341-346. http://dx.doi.org/10.2340/16501977-1122

[8] van de Sandt-Koenderman, M.E., van der Meulen, I. and Ribbers, G.M. (2012) Aphasia Rehabilitation: More than Treating the Language Disorder. Archives of Physical Medicine and Rehabilitation, 93, S1-S3. http://dx.doi.org/10.1016/j.apmr.2011.08.037

[9] Northcott, S., Moss, B., Harrison, K. and Hilari, K. (2016) A Systematic Review of the Impact of Stroke on Social Support and Social Networks: Associated Factors and Patterns of Change. Clinical Rehabilitation, 30, 811-831. http://dx.doi.org/10.1177/0269215515602136

[10] Cruice, M., Worrall, L. and Hickson, L. (2010) Health-Related Quality of Life in People with Aphasia: Implications for Fluency Disorders Quality of Life Research. Journal of Fluency Disorders, 35, 173-189. http://dx.doi.org/10.1016/j.jfludis.2010.05.008 
[11] Clarke, D.J. (2010) Achieving Teamwork in Stroke Units: The Contribution of Opportunistic Dialogue. Journal of Interprofessional Care, 24, 285-297.

http://dx.doi.org/10.3109/13561820903163645

[12] World Health Organization (2015) Noncommunicable Diseases: Fact Sheet. http://www.who.int/mediacentre/factsheets/fs355/en/

[13] World Health Organization (2016) International Classification of Functioning, Disability and Health: Children and Youth Version: ICF. http://apps.who.int/classifications/icfbrowser/

[14] Knight, K., Worrall, L. and Rose, T. (2006) The Provision of Health Information to Stroke Patients within an Acute Hospital Setting: What Actually Happens and How Do Patients Feel about It? Topics in Stroke Rehabilitation, 13, 78-98. http://dx.doi.org/10.1310/FC6M-P7L0-W3XD-4WAE

[15] Moher, D., Liberati, A., Tetzlaff, J. and Altman, D.G. (2009) Preferred Reporting Items for Systematic Reviews and Meta-Analyses: The PRISMA Statement. PLoS Medicine, 6, e1000097. http://dx.doi.org/10.1371/journal.pmed.1000097

[16] David, M., Alessandro, L., Jennifer, T., Douglas, G.A. and Prisma, G. (2014) Preferred Reporting Items for Systematic Reviews and Meta-Analyses: The PRISMA Statement. Revista Española de Nutrición Humana y Dietética, 18, 172-181.

[17] Leiknes, I., Lien, U.T. and Severinsson, I.E. (2015) The Relationship between Caregiver Burden, Demographic Variables, and the Clinical Characteristics of Patients with Parkinson's Disease-A Systematic Review of Studies Using Various Caregiver Burden Instruments. Open Journal of Nursing, 5, 855-877. http://dx.doi.org/10.4236/ojn.2015.510091 http://file.scirp.org/pdf/OJN_2015101613422424.pdf

[18] Fens, M., Beusmans, G., Limburg, M., van Hoef, L., van Haastregt, J., Metsemakers, J., et al. (2015) A Process Evaluation of a Stroke-Specific Follow-Up Care Model for Stroke Patients and Caregivers: A Longitudinal Study. BMC Nursing, 14, 3. http://dx.doi.org/10.1186/s12912-014-0052-8

[19] Matos, M.A.C., Jesus, L.M.T. and Cruice, M. (2014) Consequences of Stroke and Aphasia According to the ICF Domains: Views of Portuguese People with Aphasia, Family Members and Professionals. Aphasiology, 28, 771-796. http://dx.doi.org/10.1080/02687038.2014.906561

[20] Philp, I., Brainin, M., Walker, M.F., Ward, A.B., Gillard, P., Shields, A.L., et al. (2013) Development of a Poststroke Checklist to Standardize Follow-Up Care for Stroke Survivors. Journal of Stroke and Cerebrovascular Diseases, 22, e173-e180. http://dx.doi.org/10.1016/j.jstrokecerebrovasdis.2012.10.016

[21] Schjolberg, A. and Sunnerhagen, K.S. (2012) Unlocking the Locked in, a Need for Team Approach in Rehabilitation of Survivors with Locked-In Syndrome. Acta Neurologica Scandinavica, 125, 192-198. http://dx.doi.org/10.1111/j.1600-0404.2011.01552.x

[22] Ross, S., Barton, J. and Read, J. (2009) Staff In-Service Training on Post-Stroke Psychological and Communication Issues. International Journal of Therapy and Rehabilitation, 16, 342-348. http://dx.doi.org/10.12968/ijtr.2009.16.6.42437

[23] Smith, L.N., Craig, L.E., Weir, C.J. and McAlpine, C.H. (2008) The Evidence-Base for Stroke Education in Care Homes. Nurse Education Today, 28, 829-840. http://dx.doi.org/10.1016/j.nedt.2008.02.002

[24] Threats, T.T. (2006) Towards an International Framework for Communication Disorders: Use of the ICF. Journal of Communication Disorders, 39, 251-265.

http://dx.doi.org/10.1016/j.jcomdis.2006.02.002 
[25] Hankey, G.J. (2013) The Global and Regional Burden of Stroke. The Lancet Global Health, 1, e239-e240. http://dx.doi.org/10.1016/s2214-109x(13)70095-0

\section{Submit or recommend next manuscript to SCIRP and we will provide best service} for you:

Accepting pre-submission inquiries through Email, Facebook, LinkedIn, Twitter, etc. A wide selection of journals (inclusive of 9 subjects, more than 200 journals)

Providing 24-hour high-quality service

User-friendly online submission system

Fair and swift peer-review system

Efficient typesetting and proofreading procedure

Display of the result of downloads and visits, as well as the number of cited articles

Maximum dissemination of your research work

Submit your manuscript at: http://papersubmission.scirp.org/

Or contact ojn@scirp.org 